\title{
Laboratory Study on Corrosion Mechanism of Production System in In Situ Combustion
}

\author{
Haiyan Jiang $\mathbb{D},{ }^{1,2}$ Shibao Yuan $\mathbb{D}^{1,2}$ Hao Wang ${ }^{1},{ }^{1}$ Boyi Wang, ${ }^{1,3}$ and Jiao Wang ${ }^{1}$ \\ ${ }^{1}$ College of Petroleum Engineering, Xi'an Shiyou University, Xi'an 710065, China \\ ${ }^{2}$ Shaanxi Key Laboratory of Advanced Stimulation Technology for Oil \& Gas Reservoirs, Xi'an 710065, China \\ ${ }^{3}$ Beijing Gas Group Co., Ltd., Beijing 100035, China
}

Correspondence should be addressed to Haiyan Jiang; upcjhy@126.com

Received 23 July 2020; Revised 15 August 2020; Accepted 2 September 2020; Published 26 September 2020

Academic Editor: Guanglong Sheng

Copyright (C) 2020 Haiyan Jiang et al. This is an open access article distributed under the Creative Commons Attribution License, which permits unrestricted use, distribution, and reproduction in any medium, provided the original work is properly cited.

\begin{abstract}
The corrosion problem of a production system has been affecting the normal operation of an in situ combustion project. Because the environment of production system is significantly different in tubing, gas, liquid, and temperature in in situ combustion, the problem of the corrosion should be treated differently according to its origin. Based on the main environment of gas-liquid of the production system of in situ combustion, the corrosion of steel in N80 and J95, which are commonly used in oilfield, is studied in different temperature and pressure conditions. The results show that under the condition of $50^{\circ} \mathrm{C}$ and $3 \mathrm{MPa}$, the corrosion of the well is the most serious. Based on the analysis of corrosion causes in the production system, the corrosion under the protection of modified sacrificial anode in the liquid phase environment was studied. The results of comparative analysis show that the modified material had the dual protection effect of sacrificial anode and film-forming protection and could slow down the corrosion in different temperature ranges.
\end{abstract}

\section{Introduction}

In recent years, the international crude oil price fluctuates violently. In order to maintain the stable relationship between supply and demand of crude oil market, the development of conventional reservoirs in China has been increasing, resulting in the gradual reduction of underground reserves, and the water cut of most old oilfields has risen to a high level [1]. Therefore, the development of unconventional reservoirs which are difficult to develop has attracted many researchers' attention, and the development of heavy oil reservoir and oil shale is one of the important research directions. In situ combustion (ISC) is a promising heavy oil reservoir further EOR technology [2]; the large-area field tests of ISC technology have achieved very significant production increases in Liaohe, Xinjiang, and Suplacu oilfields [3]. At present, the application of ISC technology in oil shale development is also in progress [4]. The technology of ISC is a process that the ground compressed air is continuously injected into the oil reservoir. Then, the compressed air contacts and mixes with the oil in the reservoir. Finally, the mixture is ignited to achieve the purpose of oil displacement in the ISC process.

Due to the need for a large amount of air as an injection agent, corrosion problems inevitably occurred in the ISC production system. And casing corrosion problem is particularly serious for production wells without the specific anticorrosion measures [5]. According to statistics, after one month of air injection in gas injection well, corrosion and fracture of tubing will occur in production well [6]. Zhou et al. analyzed the fracture reason of N80-1 tubing in the ISC process of heavy oil in Xinjiang and suggested to select Cr-Mo series special tubing for the ISC process [7]. Ji et al. pointed out that the corrosion products on the surface of oil tubing during the ISC process are mainly $\mathrm{FeCO}_{3}$ and the sulfide of Fe [8]. Song et al. studied the corrosion mechanism of $35 \mathrm{CrMo}$ steel under the condition of the tail gas of ISC in Xinjiang Oilfield [9]. The results showed that 35CrMo steel 
TABLE 1: Analysis results of gas/liquid samples in the production system.

\begin{tabular}{lccc}
\hline & Gas samples & & \multicolumn{2}{c}{ Water samples } & Production wells \\
Analysis items & Production wells & Analysis items & 7.4 \\
$\mathrm{O}_{2}(\%)$ & 1.24 & $\mathrm{pH}$ & 24.3 \\
$\mathrm{CO}(\%)$ & 0.03 & $\mathrm{Mg}^{2+}$ & 8.4 \\
$\mathrm{CO}_{2}(\%)$ & 19.40 & $\mathrm{Ca}^{2+}$ & 0.02 \\
$\mathrm{~N}_{2}(\%)$ & 72.20 & $\mathrm{Fe}^{2+}, \mathrm{Fe}^{3+}$ & $\mathrm{Na}^{+}, \mathrm{K}^{+}$ \\
Calorific value $\left(\mathrm{kcal} / \mathrm{m}^{3}\right)$ & 988 & $\mathrm{Cl}^{-}$ & 518.2 \\
Density $\left(\mathrm{kg} / \mathrm{m}^{3}\right)$ & 1.3912 & $\mathrm{SO}_{4}^{2-}$ & 506.0 \\
$\mathrm{H}_{2} \mathrm{~S}(\mathrm{ppm})$ & 29 & $\mathrm{HCO}_{3}^{-}$ & 1.5 \\
$\mathrm{SO}_{2}(\mathrm{ppm})$ & 0.0 & $\mathrm{SiO}_{2}$ & 542.9 \\
& & & 17.5 \\
\hline
\end{tabular}

suffered uniform corrosion under the experimental conditions, and the gas composition had the greatest influence on the corrosion rate, followed by temperature and total pressure. If the corrosion problems cannot be solved, it will not achieve the long-term purpose of ISC.

In order to solve the corrosion problem of the ISC production system, it is necessary to analyze the gas-liquid environment of the ISC production system first. Then, based on the analysis results of the gas-liquid environment, the corrosion mechanism and law of the tubing material in the ISC production system are studied. Based on the corrosion research results, the anticorrosion measures are proposed and the anticorrosion effect is evaluated, which is also the key to ensure the smooth implementation of the whole ISC oil recovery technology.

\section{The Environmental Analysis of the Production System in ISC}

Compared with the injection system, the gas-liquid environment of the production system is more complex. The gas in the injection system mainly contains compressed air, which contains a small amount of moisture. The gas in the production system is a mixed gas (contains $\mathrm{CO}_{2}, \mathrm{CO}$, and $\mathrm{O}_{2}$ ) generated by the combustion reaction of air and crude oil in the oil reservoir [10] and the water in the production system, and the content of various acid ions is higher (due to the dissolution of $\mathrm{CO}_{2}$ in water), which makes the string of the production system more susceptible to corrosion damage. Therefore, it is necessary to analyze the environment of the production system.

Production well tubes generally have two types: N80 steel and $\mathrm{J} 55$ steel. The temperature is $30^{\circ} \mathrm{C} \sim 150^{\circ} \mathrm{C}$ from the wellhead to the bottom. Wellhead pressure is $1 \sim 3 \mathrm{MPa}$ in production wells with a produced mixture of oil, water, and gas. The gas comprises the original gas from the formation and the tail gas generated by the combustion. For this, detailed component analysis is performed on the produced water and produced gas, as shown in Table 1.

A typical production system environment is characterized by gas, water, and higher temperatures. Compared to the compressed air for injection, the main features of produced gas are high $\mathrm{CO}_{2}$ content and containing a small amount of $\mathrm{H}_{2} \mathrm{~S}$ and $\mathrm{SO}_{2}$. Produced water presents a weak acid. And ion content is generally higher in the air condensation. However, the environmental temperature of the production system is from high $\left(150^{\circ} \mathrm{C}\right)$ to low $\left(30^{\circ} \mathrm{C}\right)$ from the underground to the ground.

The production well contains about $20 \%$ carbon dioxide, about $1.3 \%$ oxygen, and a small amount of $\mathrm{H}_{2} \mathrm{~S}$ corrosive gas. In the case of water production from production wells, it will have the corrosion characteristics of $\mathrm{CO}_{2}-\mathrm{H}_{2} \mathrm{O}-\mathrm{O}_{2}$. The presence of a small amount of dissolved oxygen will become the accelerator of $\mathrm{CO}_{2}-\mathrm{H}_{2} \mathrm{O}$ corrosion.

In the complex environment and reaction, the corrosion law of N80 steel and J55 steel pipe, which are commonly used in oil field, and how to avoid or slow down the corrosion process need to be analyzed carefully through the static weightloss test.

\section{Experiment for the Corrosion Law of Production Well Material}

3.1. The Conditions of Corrosion Experiments. The experiment was carried out in a high pressure corrosion test reactor. The lower part of the experimental reactor to install a heat trace system to regulate the temperature of the experimental environment. The outer wall was surrounded by the thermal insulation material. The bottom of the experimental reactor cavity was equipped with an agitator (setting rotational speed with $200 \mathrm{r} / \mathrm{min}$ ). An external high pressure produced gas source, and an electrochemical measurement device is connected. Experimental materials are N80 steel and $J 55$ steel coupons; the size of steel coupons is $50 \mathrm{~mm} \times$ $10 \mathrm{~mm} \times 3 \mathrm{~mm}$, as shown in Figure 1 . The corrosion environment is the $\mathrm{NaHCO}_{3}$-type formation water. Experimental pressures are set at $1 \mathrm{MPa}, 2 \mathrm{MPa}$, and $3 \mathrm{MPa}$. Five experimental temperature points are set at $30^{\circ} \mathrm{C}, 50^{\circ} \mathrm{C}, 75^{\circ} \mathrm{C}$, $100^{\circ} \mathrm{C}$, and $150^{\circ} \mathrm{C}$. Each experiment was performed for 24 hours. The high pressure corrosion test reactor is shown in Figures 2(a) and 2(b).

3.2. The Results of Corrosion Experiments. Refer to China National Standards (GB/T 19291-2003 and GB/T 165451996), take the rotary coupon weight loss test, and remove corrosion products on the specimen after the experiment. Experimental environment is liquid phase. The corrosion rates of N80 steel and J55 steel are shown in Figures 3(a) 


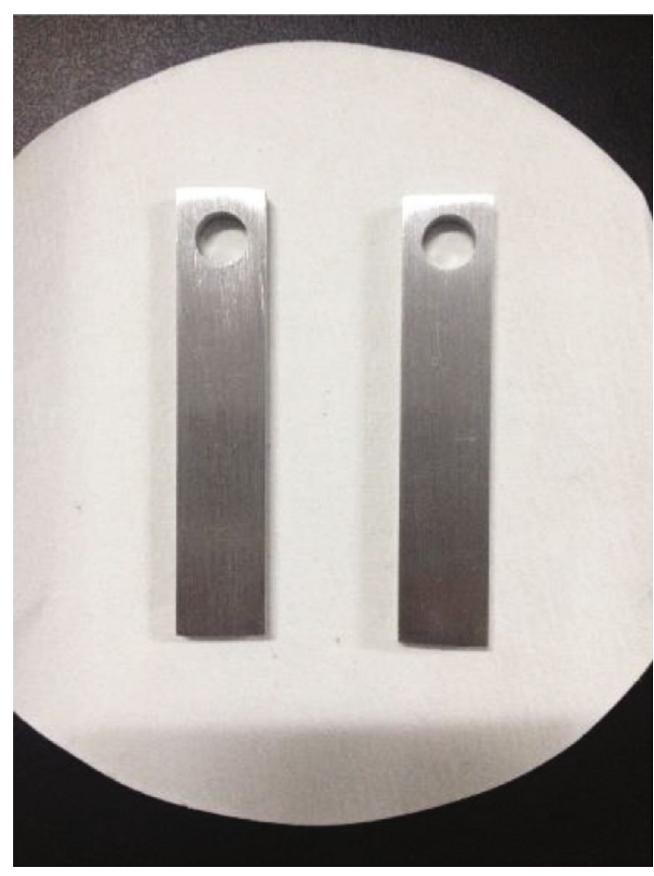

Figure 1: Steel coupons for experiment.

and 3(b), respectively. When the pressure is $1 \mathrm{MPa}$, the corrosion rate of $\mathrm{N} 80$ and $\mathrm{J} 55$ steel has the trend to increase slowly with temperature. When the pressure is 2 and $3 \mathrm{MPa}$, as the temperature increases, the corrosion rate of N80 and J55 steel first increases rapidly, then decreases rapidly, and finally reaches a relatively stable state; the corrosion rates of $\mathrm{N} 80$ and $\mathrm{J55}$ steel reach the maximum value at $50^{\circ} \mathrm{C}$. For the different trends of corrosion rate with temperature at $1 \mathrm{MPa}$ and 2 and $3 \mathrm{MPa}$, it can be explained that the corrosion rate is not sensitive to temperature at low pressure, but sensitive to temperature at high pressure. In addition, when the temperature exceeds $100^{\circ} \mathrm{C}$, the corrosion rate under different pressures is relatively close and low. And because the dense protective film of corrosion product at high temperature is easier to form [11], the corrosion rate at high temperature is lower. The most serious corrosion of the production well system occurs in $50^{\circ} \mathrm{C}$ and $3 \mathrm{MPa}$ with the liquid phase. The corrosion rates of $\mathrm{N} 80$ and 555 steel are, respectively, $9.6412 \mathrm{~mm} / \mathrm{a}$ and $13.1217 \mathrm{~mm} / \mathrm{a}$. They both far exceed the standard with 127-173 times.

The production well contains nearly $20 \%$ of $\mathrm{CO}_{2}$, about $1.3 \%$ of $\mathrm{O}_{2}$, and a small amount of $\mathrm{H}_{2} \mathrm{~S}$ corrosive gas. The corrosion is characterized by $\mathrm{CO}_{2}-\mathrm{H}_{2} \mathrm{O}-\mathrm{O}_{2}$ with water produced. Few dissolved oxygen will become the accelerator of $\mathrm{CO}_{2}-\mathrm{H}_{2} \mathrm{O}$ corrosion. In Figure 4, from the results of the corrosion test in production water and the surface of the coupons, it can be concluded that the corrosion of the material has typical characteristics of carbon dioxide corrosion. The degree of corrosion is very serious, and the rate of corrosion is about $13.1217 \mathrm{~mm} / \mathrm{a}\left(3 \mathrm{MPa}, 50^{\circ} \mathrm{C}\right.$, J55 steel).

In the absence of electrolyte, $\mathrm{CO}_{2}$ will not corrode metals, which indicates that $\mathrm{CO}_{2}$ corrosion is electrochemical corrosion. This kind of corrosion is mainly caused by the forma- tion of carbonic acid from $\mathrm{CO}_{2}$ dissolved in water in production wells.

In the presence of oxygen, $\mathrm{FeO}$ will be oxidized to generate $\mathrm{Fe}_{2} \mathrm{O}_{3}$ :

$$
4 \mathrm{FeO}+\mathrm{O}_{2} \rightarrow 2 \mathrm{Fe}_{2} \mathrm{O}_{3}
$$

When the medium contains $\mathrm{CO}_{2}$ or water vapor, $\mathrm{FeO}$ will react to generate $\mathrm{Fe}_{3} \mathrm{O}_{4}$ :

$$
\begin{aligned}
& 3 \mathrm{FeO}+\mathrm{CO}_{2} \rightarrow \mathrm{Fe}_{3} \mathrm{O}_{4}+\mathrm{CO} \\
& 3 \mathrm{FeO}+\mathrm{H}_{2} \mathrm{O} \rightarrow \mathrm{Fe}_{3} \mathrm{O}_{4}+\mathrm{H}_{2}
\end{aligned}
$$

When $\mathrm{Fe}_{3} \mathrm{O}_{4}$ is exposed to oxygen, it will be converted into $\mathrm{Fe}_{2} \mathrm{O}_{3}$ :

$$
4 \mathrm{Fe}_{3} \mathrm{O}_{4}+\mathrm{O}_{2} \rightarrow 6 \mathrm{Fe}_{2} \mathrm{O}_{3}
$$

By reactions (1), (2), (3), and (4), $\mathrm{FeCO}_{3}$ eventually transformed into the form of $\mathrm{Fe}_{2} \mathrm{O}_{3}$ with the presence of residual oxygen. And the nature of this $\mathrm{FeCO}_{3}$ film has a significant impact on the corrosion rate. The dissolution rate of iron in $\mathrm{CO}_{2}$ solution increases with temperature in a certain range. But when the temperature is high and ferrous carbonate is formed on the surface of iron, iron dissolution rate decreases with temperature increasing. There are three temperature zones in $\mathrm{CO}_{2}$ corrosion. In low temperature zone less than $60^{\circ} \mathrm{C}$, the corrosion rate increases with temperature since the corrosion product film is loose and not dense. In middle temperature zone at up to $100^{\circ} \mathrm{C}$, the corrosion rate reaches the maximum value at this point, because the $\mathrm{FeCO}_{3}$ film is coarse and pitting corrosion is generated by crystallizing, cracking and peeling. When the temperature increase to $150^{\circ} \mathrm{C}$ called high-temperature zone, iron corrosion rate significantly decreased. $\mathrm{Fe}^{2+}$ and $\mathrm{CO}_{3}{ }^{2-}$ ions are easy to form a thin but dense protective film of $\mathrm{FeCO}_{3}$. Temperature also has a significant impact on the composition of the corrosion product film. It is generally believed that the corrosion product film is composed of the $\mathrm{Fe}_{3} \mathrm{C}$ and $\mathrm{FeCO}_{3}$. The $\mathrm{Fe}_{3} \mathrm{C}$ is a residual component of corrosion production after Fe corroded, and it will not be corroded in corrosive medium containing $\mathrm{CO}_{2}$, while the amount of $\mathrm{FeCO}_{3}$ increases with temperature.

\section{Performance Comparison Test of Sacrificial Anode Protection Method}

In oilfield practice, the inhibitor needs to be continuously added to the target well section in the wellbore [12]. Thick crude oil often accumulates in the top layer of the annulus solution of the oil jacket, which prevents the inhibitor from playing its role [13]. The anticorrosion effect is also greatly affected by the adding means and operation method. The protection range of the common sacrificial anode is about 10 times the diameter of the pipe. So it is difficult to ensure the anticorrosion effect $[14,15]$. Therefore, the modified material is added in the sacrificial anode. With it, the $\mathrm{Al}(\mathrm{OH})_{3}$ protective film is formed on the surface of the tube 


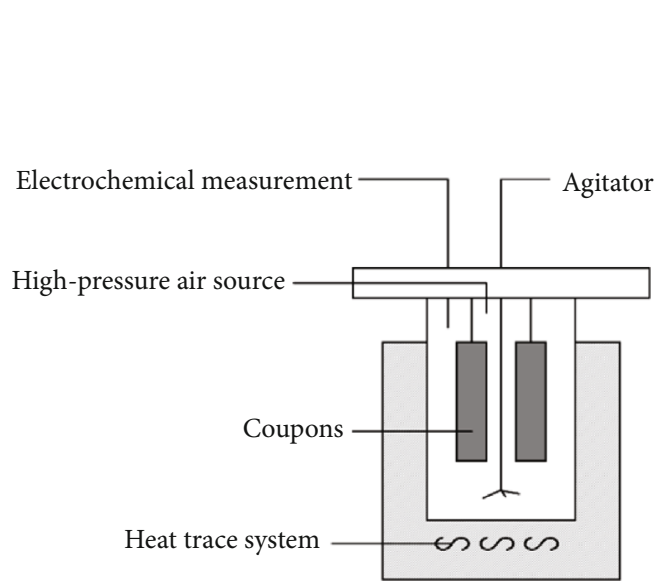

(a)

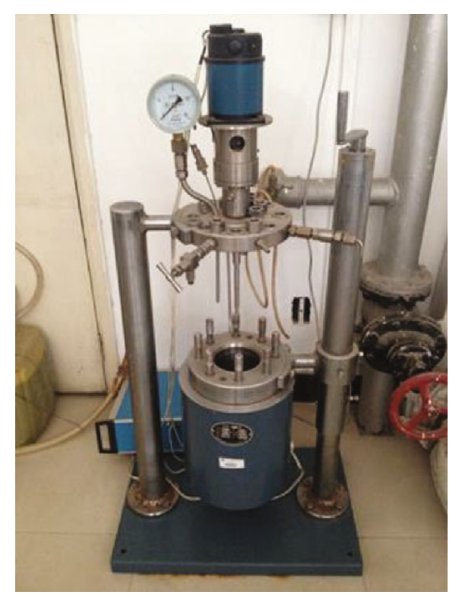

(b)

Figure 2: High pressure corrosion test reactor.

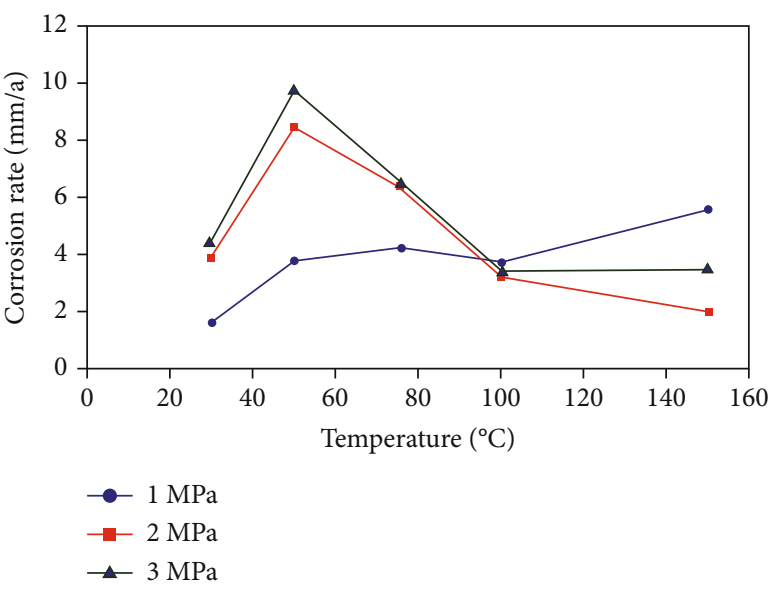

(a)

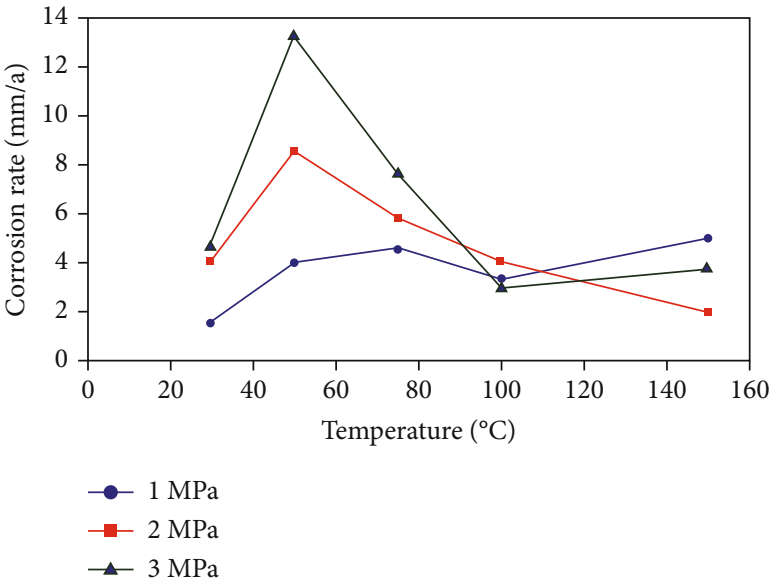

(b)

FIgURE 3: The variation of corrosion rate with temperature in liquid phase. (a) N80, (b) J55.

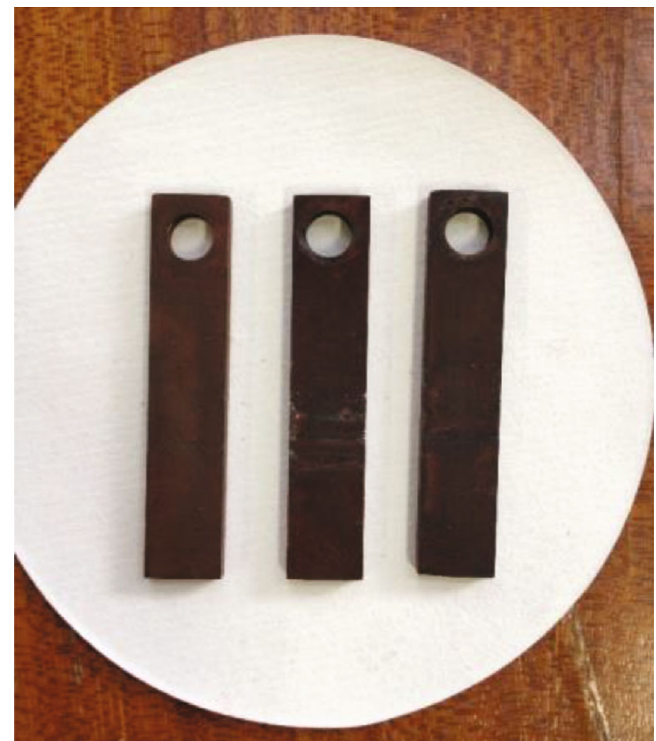

Figure 4: Coupon after experiment. and the rod, which greatly improves the protection distance and effect.

4.1. Anticorrosion Principle of Sacrificial Anode. Sacrificial anode protection integrates two effects of sacrificial anode protection and protective film. In the protection process, the aluminum anode, oil tube, and sucker rod form a primary battery in wellbore solution. Aluminum is relatively active, and it loses electrons prior to iron; that is, aluminum anode is preferentially consumed by corrosion, protecting the oil tube and sucker rod. In the process of sacrificial anode protection, there are three reactions: cathode reaction, anode reaction, and film formation.

$$
\text { Anodic process }: \mathrm{Al} \rightarrow \mathrm{Al}^{3+}+3 \mathrm{e}^{-}
$$

Cathodic process : $\mathrm{O}_{2}+2 \mathrm{H}_{2} \mathrm{O}+4 \mathrm{e}^{-} \rightarrow 4 \mathrm{OH}^{-}$

Film-forming process : $\mathrm{Al}^{3}+3 \mathrm{OH}^{-} \rightarrow \mathrm{Al}(\mathrm{OH})_{3}$

The $\mathrm{Al}(\mathrm{OH})_{3}$, which is the secondary reaction product of aluminum anode, can be adsorbed on the tubing wall and 


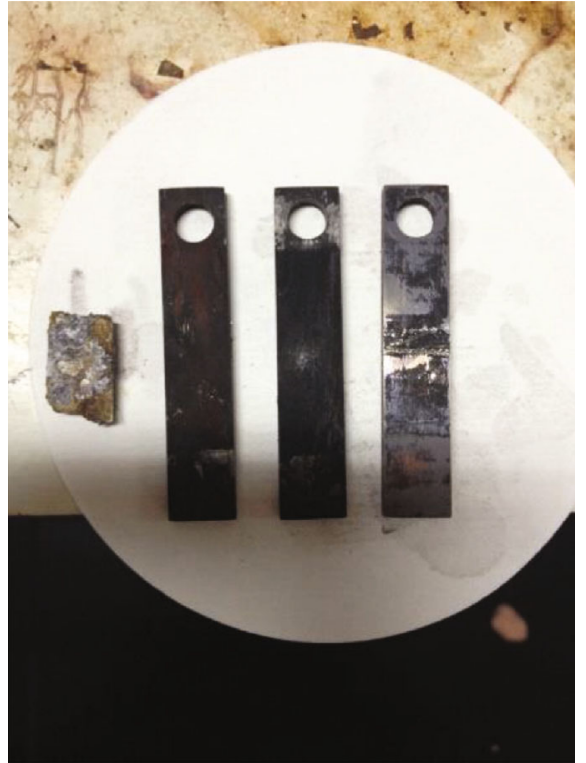

(a)

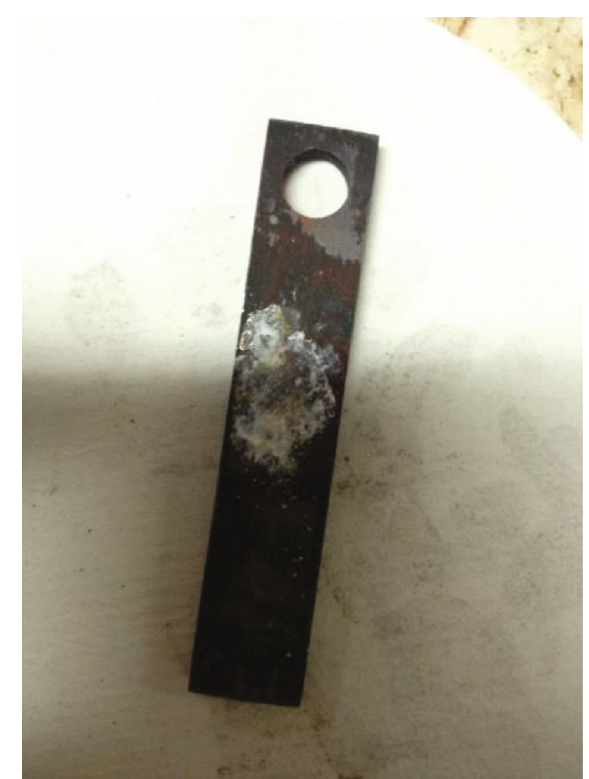

(b)

FIgURE 5: Pictures of experimental coupons.

sucker rod, so that oxygen can be reduced on iron only through $\mathrm{Al}(\mathrm{OH})_{3}$ film; that is to say, the diffusion of oxygen to tubing wall or sucker rod is isolated, and corrosion inhibition effect is achieved. The film-forming function greatly extends the anticorrosion protection range.

\subsection{Preparation and Evaluation of Sacrificial Anode}

4.2.1. Requirements of Experiment. An N80 carbon steel test piece is used for the cathode, and a modified sacrificial anode material is used for the anode. The corrosion environment is the $\mathrm{NaHCO}_{3}$-type formation water. Total salinity is $3810 \sim 8760 \mathrm{mg} / \mathrm{L}$.

4.2.2. Experimental Method. In order to verify the protective effect of sacrificial anode, the protective effect was evaluated by, respectively, comparing the experimental results with the temperature of $27^{\circ} \mathrm{C}, 90^{\circ} \mathrm{C}$, and $110^{\circ} \mathrm{C}$.

4.3. The Analysis of Experimental Results of Sacrificial Anode. In the experiment, $\mathrm{A} 1$ and $\mathrm{A} 2$ are denoted as corrosion of unprotected coupons under natural conditions. A3 is a protected coupon by the modified sacrificial anode.

The liquid inside the reactor before the experiment was clarified. After seven days of the experiment period, it turned to red-brown. And the experiment coupons were then take out to be observed and weighed.

As shown in Figure 5(a), from left to right are the unprotected coupons (A1 and A2) under the natural corrosion condition. The last is the protected coupon (A3) by the modified sacrificial anode. From Figure 5(a), we can clearly see that at the end of the experiment the unprotected coupons (A1 and A2) have lost the original metallic luster and shown black color after corrosion, while the protected coupon (A3) is mostly with metallic luster and only a small part is corroded.

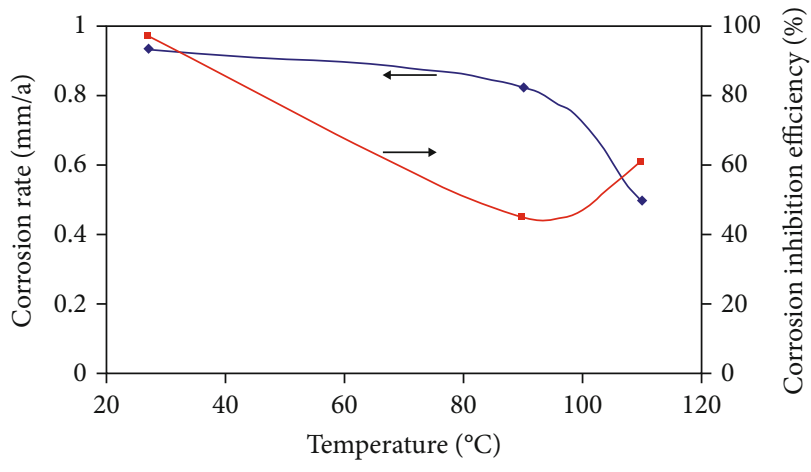

FIGURE 6: Curve of temperature with corrosion rate under modified sacrificial anode protection.

The protected coupon (A3) is shown before being cleaned as shown in Figure 5(b). It can be seen that some white powder was attached to the coupon where the modified anode was connected. And it illustrates that the $\mathrm{Al}(\mathrm{OH})_{3}$ protective film is formed on the cathode. The cathode is effectively protected.

In order to further analyze the anticorrosion effect. The corrosion rate of each group was calculated under different temperature conditions. The experiment was carried out on the $2 \mathrm{MPa}$ environment for 80 hours. The specific experimental parameters and data are shown in Figure 6.

As shown in Figure 6, from the perspective of corrosion rate and corrosion inhibition efficiency, the modified sacrificial anode protection method plays a significant role in corrosion protection. When the temperature is relatively low at $27^{\circ} \mathrm{C}$, the corrosion rate is the highest, and the anticorrosion effect is the most prominent. At $90^{\circ} \mathrm{C}$, the corrosion rate is the lowest, and the anticorrosion effect is the worst. When the temperature is above $100^{\circ} \mathrm{C}$, the corrosion inhibition rate increases gradually. Under the protection of modified 
sacrificial anode, the corrosion rate shows a downward trend with the increase of temperature; the corrosion rate decreases slowly below $90^{\circ} \mathrm{C}$ and decreases rapidly above $90^{\circ} \mathrm{C}$. At the same time, the corrosion inhibition efficiency showed a relatively rapid decrease and then a rapid increase trend with the cut-off point at $90^{\circ} \mathrm{C}$. The change of temperature has a great influence on the protective effect of the sacrificial anode [16-18]. Since the intergranular corrosion occurs in high temperature, the anode corrosion inhibition efficiency decreases as the temperature increases. The phenomenon which is the increase of corrosion inhibition efficiency above $90^{\circ} \mathrm{C}$ is expected. The analysis believes that the increase of corrosion inhibition efficiency above $90^{\circ} \mathrm{C}$ is mainly due to the accelerated formation of the dense protective film of corrosion products at high temperature.

\section{Conclusions}

In this research, the corrosion mechanism and anticorrosion method of ISC production system are studied. Based on the simulated gas-liquid environment of the ISC production system in the laboratory, the corrosion experiments under different temperature and pressure conditions were carried out, and the anticorrosion effectiveness of the modified sacrificial anode method was studied. The research results can provide guidance for the formulation of anticorrosion measures for the ISC production system. The following conclusions are drawn:

(1) Residual oxygen and $\mathrm{CO}_{2}$ in the tail gas of ISC are the main causes for corrosion of pipes. $\mathrm{CO}_{2}$ corrosion has three temperature zones. And the corrosion rate in different zones presents different temperaturedependent characteristics

(2) The modified sacrificial anode method can be effectively used in the production tubes by ISC. And the anticorrosion effect is significant. Since the wellhead temperature is low in production wells, the effect of the wellhead section is better than that of the bottom. Corrosion inhibition rate can reach the highest value (96.87\%)

(3) Considering the complex working conditions of the production wells, the modified sacrificial anode protection method is recommended as the first choice for corrosion protection measures

\section{Data Availability}

The data used to support the findings of this study are available from the corresponding author upon request.

\section{Conflicts of Interest}

The authors declare that they have no conflicts of interest.

\section{Acknowledgments}

This work is funded by the National Natural Science Foundation of China (No. 51674198).

\section{References}

[1] S. Fu, Y. Zhang, R. Liu, and Z. Zheng, "Research progress of thermal recovery technology in heavy oil and super heavy oil reservoir," Energy Chemical Industry, vol. 41, no. 2, pp. 26-31, 2020.

[2] K. Ning, S. Yuan, and H. Jiang, In-Situ Combustion Theory \& Practice, China University of Petroleum Press, Dongying, Shandong, P. R. CHINA, 2010.

[3] J. Huang, W. Guan, C. Xi, H. Cheng, X. Li, and Y. Wang, "Production performance of in-situ combustion in heavy oil reservoir after steam injection," Xinjiang Petroleum Geology, vol. 31, no. 5, pp. 517-520, 2010.

[4] H. Zheng, W. Shi, D. Ding, and C. Zhang, "Numerical simulation of in situ combustion of oil shale," Geofluids, vol. 2017, Article ID 3028974, 9 pages, 2017.

[5] Q. Zhou, S. Ren, H. Yu et al., "Implantation technique of corrosion inhibitor for air injection EOR," Total Corrosion Control, vol. 30, no. 10, pp. 745-746+760, 2009.

[6] Q. Zhou, Corrosion and anti-corrosion techniques for air injection EOR process MS Thesis, China University of Petroleum, 2009.

[7] Y. Zhou, W. Xia, and Y. Zhao, "Analysis on causes for failure of N80-1 tubing as occurring during process of heavy oil fireflooding exploitation," Steel, vol. 47, no. 4, pp. 18-22, 2018.

[8] L. Ji, L. Chen, P. Zhang, and Y. Zhang, "Failure analysis of oil pipe fracture in an old well production converting from thermal recovery production into fireflood production," Corrosion \& Protection, vol. 40, no. 2, 2019.

[9] X. Song, Y. Wang, J. Liang et al., "Corrosion behavior of $35 \mathrm{CrMo}$ steel under O2, $\mathrm{H} 2 \mathrm{~S}$ and $\mathrm{CO} 2$ mixed system," Natural Gas and Oil, vol. 36, no. 6, 2018.

[10] W. Lin, X. Li, X. Chen, S. An, J. Guan, and H. Li, "Corrosion and protection in air-foam injection process," Oilfield Chemistry, vol. 27, no. 3, pp. 342-345, 2010.

[11] Z. Wu, H. Fan, C. Cui, C. Wu, M. Jiang, and Y. Wang, "Study on high temperature corrosion of N80 casing caused by the emissions from ISC well," China Petroleum Machinery, vol. 44, no. 5, pp. 98-101, 2016.

[12] R. Liu, G. Yin, C. Wei et al., "Electrochemical corrosion behavior of P110 tubing steel in annular environment," Corrosion Science and Protection Technology, vol. 25, no. 6, pp. 451$455,2013$.

[13] Y. Zhu, C. Liu, F. Wang, and T. Huang, "Research on corrosion behavior of tubular steel in saturated $\mathrm{CO}_{2}$ simulated oilfield fluid," Corrosion Science and Protection Technology, vol. 23, no. 3, pp. 271-273, 2011.

[14] L. Zhao, Study on the sacrificial anode protection technology about high $\mathrm{pH}$ value and gas well with high sulfur content MS Thesis, China University of Petroleum, 2011.

[15] X. Li, H. Li, X. Chen, and W. Lin, "Morphology analysis of corrosion products in air-foam flooding process system," Corrosion \& Protection, vol. 32, no. 10, pp. 800-802, 2011.

[16] T. Liu, Evaluation of temperature resistance of magnesium alloy sacrificial anode and study on resistances to high temperature of aluminum alloy sacrificial anode MS Thesis, Huazhong University of Science \& Technology, 2019. 
[17] G. Sheng, Y. Su, and W. Wang, "A new fractal approach for describing induced-fracture porosity/permeability/compressibility in stimulated unconventional reservoirs," Journal of Petroleum Science and Engineering, vol. 179, pp. 855-866, 2019.

[18] G. Sheng, H. Zhao, Y. Su et al., "An analytical model to couple gas storage and transport capacity in organic matter with noncircular pores," Fuel, vol. 268, pp. 855-866, 2020. 